\title{
Human Neural Systems for Face Recognition and Social Communication
}

\author{
James V. Haxby, Elizabeth A. Hoffman, and M. Ida Gobbini
}

Face perception is mediated by a distributed neural system in humans that consists of multiple, bilateral regions. The functional organization of this system embodies a distinction between the representation of invariant aspects of faces, which is the basis for recognizing individuals, and the representation of changeable aspects, such as eye gaze, expression, and lip movement, which underlies the perception of information that facilitates social communication. The system also has a hierarchical organization. A core system, consisting of occipitotemporal regions in extrastriate visual cortex, mediates the visual analysis of faces. An extended system consists of regions from neural systems for other cognitive functions that can act in concert with the core system to extract meaning from faces. Of regions in the extended system for face perception, the amygdala plays a central role in processing the social relevance of information gleaned from faces, particularly when that information may signal a potential threat. Biol Psychiatry 2002;51:59-67 (C) 2002 Society of Biological Psychiatry

Key Words: Face perception, functional brain imaging, spatial attention, emotion, facial expression, semantic knowledge

\section{Introduction}

$\mathrm{T}$ he perception of faces can elicit neural activity in multiple regions in extrastriate visual cortex as well as multiple other regions in nonvisual cortices. The complexity of this distributed neural system for face perception reflects the complexity of face perception itself. Face perception is perhaps the most developed visual perceptual skill in humans and plays a critical role in social interactions. Different parts of the distributed neural system for face perception mediate different, relatively independent types of face perception. In this review, the functional anatomy of the face perception system will be described

From the Laboratory of Brain and Cognition, National Institute of Mental Health, Bethesda, Maryland.

Address reprint requests to James V. Haxby, Ph.D., Laboratory of Brain and Cognition, NIMH, Building 10, Room 4C104, 10 Center Drive-MSC 1366, Bethesda MD 20892-1366.

Received September 25, 2001; revised October 24, 2001; accepted October 24, 2001. and related to the cognitive organization of face perception. In particular, this review will emphasize the distinction between the perception of structural aspects of faces that are invariant across changes due to facial movements and the perception of changes due to facial movements. These two aspects of face perception are cognitively independent and can be dissociated anatomically. The perception of invariant aspects of face structure underlies the recognition of individuals. The perception of changes due to facial movements, on the other hand, plays a more central role in social communication. This review will also discuss the role played by other neural systems in face perception, such as systems that mediate shifts of spatial attention or mediate auditory verbal comprehension. In particular, the participation of systems that may play a role in social anxiety will be discussed with regard to their interaction with face perception.

\section{Extrastriate Visual Cortex and Face Perception: The Core System}

Evidence from neuropsychology, neurophysiology, and cognitive development indicated that face perception may be mediated by a specialized system in the human brain long before functional brain imaging identified the specific brain structures that might participate in such a system. Neuropsychological studies of patients with prosopagnosia (Hecaen and Angelergues 1962; McNeil and Warrington 1993), a selective impairment of the ability to recognize familiar faces with relatively intact ability to recognize other objects, suggested a dissociation between neural systems that mediate face and object recognition. The lesions that cause prosopagnosia are found in ventral occipitotemporal cortex and are usually bilateral (Benton 1980; Damasio et al 1982; Sergent and Signoret 1992), although right unilateral lesions have been the cause of this syndrome in a few well-documented cases (De Renzi 1986; Landis et al 1986).

Single neuron recording studies in nonhuman primates also have provided evidence for a specialized neural system for face perception. These studies have identified neurons in the superior temporal sulcus and the inferior temporal cortex in the macaque brain that respond selec- 
tively to faces (Perrett et al 1984, 1985, 1990). The locations of these homologous regions in the human brain that are specialized for face perception, however, were not obvious.

The cognitive development of face perception also suggests a special status for face perception. Infants prefer to look at faces rather than other objects, beginning shortly after birth (Morton and Johnson 1991). The predilection of infants to imitate facial expressions at a very early age further suggests that face perception plays a central role in developing social interaction skills and language.

Functional brain imaging allows the noninvasive study of the neural systems that participate in face perception in the intact human brain. Relative to the study of patients with naturally occurring brain lesions, functional brain imaging affords far greater anatomical precision and avoids the confounding factors associated with patient studies, such as any compensatory functional reorganization of the brain. Functional imaging data can indicate which brain regions participate in a perceptual or cogntitive function and how their participation is modulated by other processes, such as attention or memory, but imaging data cannot indicate which of these brain regions are critical for the successful performance of a perceptual or cognitive operation. Studies of patients with lesions or studies of normal volunteers with virtual lesions induced by methods such as transcranial magnetic stimulation (e.g., Hilgetag et al 2001) are necessary to address the question of whether a region is a necessary participant. Functional imaging measures hemodynamic changes that are induced by changes in neural activity. Because the hemodynamic response function is relatively slow, functional imaging cannot reliably resolve neural events that are separated by less than several hundred milliseconds. Understanding the temporal dynamics of neural processes for face perception, therefore, requires methods with better temporal resolution, such as evoked potentials measured with electroencephalography (e.g., Allison et al 1999) or magnetoencephalography (e.g., Streit et al 1999).

Face perception evokes activity in a bilateral region in the lateral fusiform gyrus (Clark et al 1996; Halgren et al 1999; Haxby et al 1994, 1999; Hoffman and Haxby 2000; Ishai et al 1999; Kanwisher et al 1997; McCarthy et al 1997; Sergent et al 1992) that is greater than the activity evoked by the perception of nonsense, control stimuli, or by the perception of nonface objects (Figure 1). The location of this region has been highly consistent across numerous studies. Kanwisher et al (1997) have named this region the "fusiform face area" or FFA. They and others (McCarthy et al 1997) have proposed that this region is a module that is specialized for face perception, although other evidence suggests that the submaximal responses in this region to other objects also carry information about

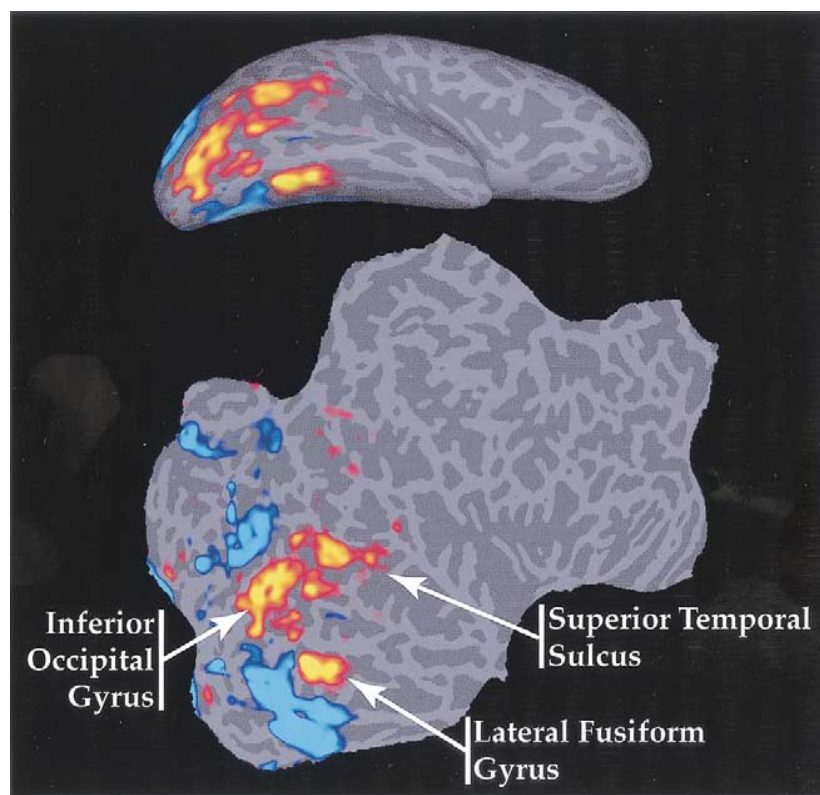

Figure 1. Locations of the regions that comprise the core system for visual analysis of faces, illustrated by functional magnetic resonance imaging results from a single subject in Haxby et al (1999). Regions shown in red to yellow responded more to faces than to houses. Regions shown in blue responded more to houses than to faces. The upper figure is an image of the cortical surface of the right hemisphere that has been tipped $45^{\circ}$ to show both the lateral and ventral surfaces of the occipital and temporal lobes and then inflated to show the cortex in the sulci, indicated by a darker shade of gray. The lower figure shows the entire cortical surface of the right hemisphere flattened into a two-dimensional sheet. Adapted from Haxby et al 2000.

the appearance of nonface objects, suggesting its function may not be restricted to face perception (Chao et al 1999b; Haxby et al 2001; Ishai et al 1999). Gauthier and her colleagues have argued that this region is specialized for visual expertise, not just for face recognition (Gauthier et al 1999). They propose that these regions will respond to any objects that the subject perceives as distinct individuals rather than as generic exemplars of a category. Faces consistently activate these regions because practically everyone is an expert at face recognition. In a functional magnetic resonance imaging (fMRI) study of expertise for other categories of objects, Gauthier et al found that the response to birds and cars was augmented in the fusiform face-responsive region in subjects with expertise at recognizing these categories relative to nonexperts (Gauthier et al 2000), although the responses evoked by expert viewing of nonface objects were not equivalent to the responses to faces. These results suggest that the face-responsive region in the fusiform gyrus may also participate in the perception of other object categories, especially when those objects are recognized at the subordinate level, as unique individuals, rather than at the category level. 
Functional imaging studies have identified face-responsive regions in addition to the region in the fusiform gyrus. These regions are also in visual extrastriate cortex and are found in the lateral inferior occipital gyri and the posterior superior temporal sulcus (Halgren et al 1999; Haxby et al 1999; Hoffman and Haxby 2000; Kanwisher et al 1997; Puce et al 1998) (Figure 1). Evoked potential studies using electrodes placed on the cortical surface in patients undergoing brain surgery for temporal lobe epilepsy have shown that sites in these same cortical regions produce facespecific responses (Allison et al 1999; McCarthy et al 1999; Puce et al 1999). The relative locations of these three face-responsive regions suggest that the inferior occipital region, which lies in close proximity to the lateral fusiform region ventrally and to the superior temporal sulcal region dorsally, may provide input to both faceresponsive regions in temporal cortex (Haxby et al 1999; Hoffman and Haxby 2000).

Face perception involves the participation of multiple, bilateral regions in ventral extrastriate cortex. These visual regions constitute what we call the core system for face perception, and they appear to participate differentially in the perception of face identity and face movement and expression. An influential cognitive model of face perception by Bruce and Young (1986) emphasized a distinction between processes involved in the recognition of identity and the recognition of expression and speech-related movements of the mouth. The anatomical organization of face-responsive regions in extrastriate visual cortex provides a substrate that embodies this cognitive distinction.

Single-neuron recording studies in nonhuman primates provide some evidence for a dissociation between systems for face perception-systems for recognition of individuals and for social communication. Neurons in the macaque brain that respond selectively to faces are found in patches of cortex in the superior temporal sulcus and in the inferior temporal gyrus (Desimone 1991; Hasselmo et al 1989; Perrett et al 1982, 1984, 1985, 1990). Perrett and others have found superior temporal sulcal neurons that respond selectively to different angles of gaze and different angles of profile (Perrett and Mistlin 1990; Perrett et al 1985, 1992). Most cells that responded to a preferred gaze direction also responded to a compatible angle of profile. Gaze direction and angle of profile provide socially relevant information regarding the direction in which another individual is attending.

A dissociation between the selectivity of face-responsive cells in the superior temporal sulcus and on the convexity of the inferior temporal gyrus was found by Hasselmo et al (1989). A large proportion of face-selective cells that they studied responded selectively to identity or expression. Cells that responded differentially to different individuals did so across variations in expression, and cells that responded differentially to different expressions did so across individuals. The cells that were tuned differentially to expression were found primarily in the superior temporal sulcus. By contrast, the cells that were tuned differentially to identity were found primarily in inferior temporal cortex.

Single-neuron recording studies in the monkey suggest a dissociation between the roles played by face-selective cells in the superior temporal sulcus and inferior temporal cortex. The likely locations of human homologues for these face-responsive regions are the superior temporal sulcus and the lateral fusiform gyrus.

Functional brain imaging studies have shown consistently that a region in the posterior superior temporal sulcus is activated during the perception of biological movement, including movements of the face, such as eye and mouth movements, and movements of the whole body and hand (Bonda et al 1996; Decety and Grezes 1999; Puce et al 1998). The posterior superior temporal sulcus also is activated during the perception of still pictures of faces (Chao et al 1999a; Halgren et al 1999; Haxby et al 1999; Hoffman and Haxby 2000; Kanwisher et al 1997). This response to still pictures may reflect involvement in the perception of potential movement or the evaluation of changeable aspects of a face that can vary with movement. This sensitivity of the posterior superior temporal sulcus may be analogous to the differential tuning of neurons in the monkey superior temporal sulcus to direction of eye gaze, angle of profile, and expression (Hasselmo et al 1989; Perrett and Mistlin 1990; Perrett et al 1984, 1985, 1990, 1992).

We have demonstrated a direct dissociation between the functional roles played by the face-responsive regions in the human superior temporal sulcus and lateral fusiform gyrus in a functional magnetic resonance imaging study. In this study the response to faces was modulated by directing selective attention to direction of eye gaze or to individual identity (Figure 2). Selective attention to eye gaze evoked a stronger response in the superior temporal sulcus than did selective attention to identity. By contrast, selective attention to identity evoked a stronger response in the lateral fusiform gyrus than did selective attention to eye gaze.

\section{Nonvisual Cortices and Face Perception: The Extended System}

Face perception provides a wealth of information that facilitates social interaction. From the information gleaned from the visual appearance of faces, one can access information about the identity and background of another person; make inferences about mood, level of interest, and intentions; direct ones own attention to objects and events 


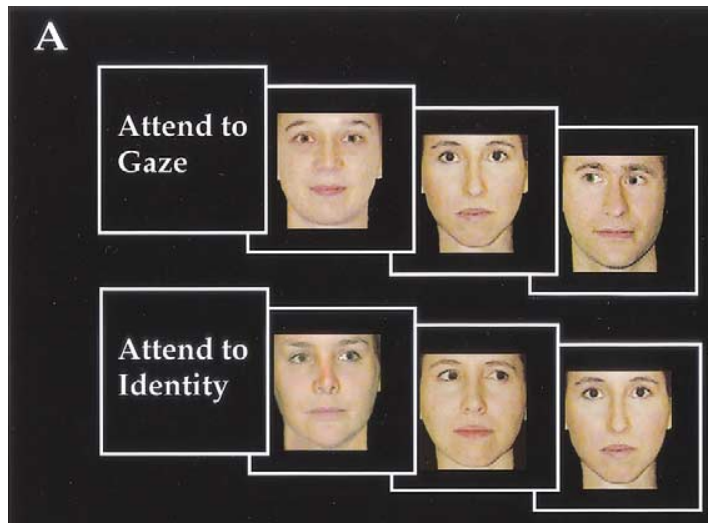

B

Superior Temporal Sulcus

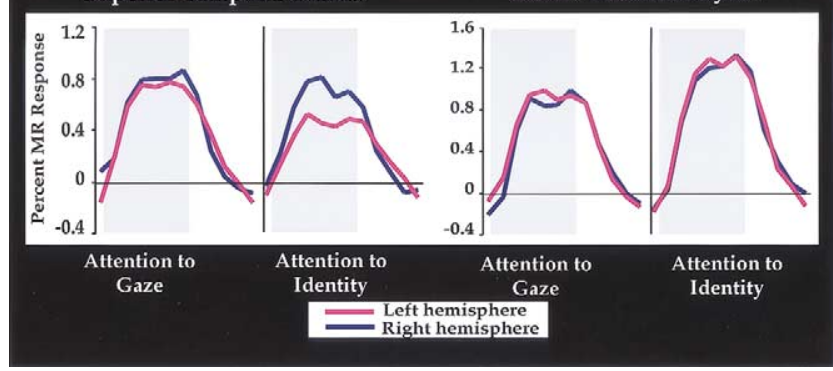

Figure 2. Direct demonstration of a double dissociation between the functional roles played by face-responsive regions in the superior temporal sulcus and the lateral fusiform gyrus (adapted from Hoffman and Haxby 2000). (A) Tasks. Subjects were instructed to attend to direction of gaze or to face identity in one-back repetition detection tasks. (B) Mean responses $(n=6)$ in the superior temporal sulcus and lateral fusiform gyrus. Gray areas indicate the time when 18 -sec blocks of the face task were presented. Blocks of the face task were separated by 18 -sec blocks of a control task in which subjects viewed scrambled, colored, nonsense images made from the face pictures. Magnetic resonance imagery intensities during the control task served as the baseline for calculating percent increases.

that others are looking at; and enhance comprehension of speech. Processing this information involves the participation of neural systems that are not necessarily dedicated to visual perception. These brain regions become part of the face perception system when they act in concert with the extrastriate face-responsive regions to extract meaning from faces and, thereby, facilitate recognition of different facial attributes.

\section{Perception of Eye Gaze Direction and Spatial Attention}

Awareness of the direction in which another person is attending provides critical information for monitoring social interactions, for directing ones own attention, and for assessing potential sources of threat. As early as 6 months of age, human infants shift their attention in the direction of anothers gaze (Hood et al 1998; Vecera and Johnson 1995). Shifting attention in response to perceived gaze direction apparently is reflexive, occurring even when subjects are told that the direction of perceived gaze is irrelevant (Driver et al 1999; Friesen and Kingstone 1998; Hietanen 1999; Langton and Bruce 1999). An averted gaze, namely a gaze that is inconsistent with head orientation, is a better stimulus for evoking a shift of attention than is a direct gaze, even if the head and gaze are directed to the side (Hietanen 1999). Shifts of attention that are elicited by perceived gaze, therefore, are not dependent on a simple detection of eye position but rather involve the integrated perception of eye and head position (Langton et al 2000).

Cross-species comparisons suggest that mechanisms for detecting eye gaze direction are more primitive and more ubiquitous than are mechanisms for mediating a shared attentional focus (Baron-Cohen 1995). The ability to perceive eye direction may have evolved to detect threat from potential predators, and evidence for this ability has been found even in nonmammalian species, such as snakes and chickens, as well as in mammals. Shared attention, on the other hand, appears to be more exclusively found in higher primates and may have evolved to facilitate interactions in complex social groups.

The superior bank of the superior temporal sulcus and the intraparietal sulcus have reciprocal connections that could mediate the transfer of information about gaze direction and head orientation to parietal neural systems for spatial attention (Harries and Perrett 1991). In the monkey, parietal cortex plays a central role in spatial perception and attention (Colby and Goldberg 1999; Ungerleider and Mishkin 1982). Cortex in the human intraparietal sulcus participates in spatial perception, spatial memory, and covert shifts of spatial attention (Corbetta 1998; Corbetta et al 1993; Haxby et al 1994; Nobre et al 1997).

In our study of selective attention to gaze direction or identity, selective attention to gaze direction also elicited a stronger response in a region in the intraparietal sulcus than did attention to identity, similar to the finding in the superior temporal sulcus (Hoffman and Haxby 2000), possibly indicating that the spatial attention system was recruited by attention to eye gaze to mediate covert shifts of attention. In a second experiment we tested this hypothesis by examining whether perceived averted gaze elicited a stronger response in the intraparietal sulcus than did perceived direct gaze. Behavioral studies have indicated that perceived averted gaze elicits a reflexive shift of spatial attention. Results showed that passive viewing of faces that have averted gazes elicited a significantly stronger response than did passive viewing of faces that have direct gazes in the intraparietal sulcus. The reflexive 
shift of spatial attention that is elicited by the perception of averted eye gaze, therefore, appears to be mediated by an interaction between the face-responsive region in the superior temporal sulcus and the spatial attention system in the intraparietal sulcus.

\section{Perception of Lip Movements and Speech Comprehension}

Speech comprehension can be facilitated or modulated by the perception of speech-associated lip movements, even in people with normal hearing. Lip reading improves hearing accuracy and lip movements that are inconsistent with auditory speech can cause hearing errors (McGurk and MacDonald 1976).

Viewing nonspeech mouth movements evokes activity in the superior temporal sulcus (Puce et al 1998), and lip reading evokes additional activity in auditory areas in the superior temporal gyrus that are also activated by hearing spoken words (Calvert et al 1997). These results indicate that the perception of speech-related lip movement involves the coordinated activity of visual regions in the superior temporal sulcus, associated with the visual analysis of lip movement, and auditory speech regions in the superior temporal gyrus, associated with the analysis of phonemic content.

\section{Perception of Identity and Retrieval of Semantic Knowledge about People}

A novel face is perceived as a unique individual even when one has no other knowledge of that person, and this perception of the unique identity of a face appears to be associated with activity in lateral fusiform gyrus (George et al 1999; Hoffman and Haxby 2000; Sergent et al 1992). The recognition of a familiar face appears to involve a fixed sequence of stages in which the retrieval of semantic information about a person precedes the retrieval of that person's name (Ellis 1992). Recognition of familiar faces appears to be associated with activity in anterior temporal regions (Gorno Tempini et al 1998; Leveroni et al 2000; Nakamura et al 2000; Sergent et al 1992), especially the anterior middle temporal gyrus. Activity in this region is also elicited by the perception of the names of famous people and by the perception of familiar outdoor scenes (Gorno Tempini et al 1998; Nakamura et al 2000), suggesting that this region may be associated with the representation of biographical knowledge.

\section{Perception of Facial Expression and Neural Systems for Processing Emotion}

The expression on another's face provides information about that person's emotional state and can evoke that
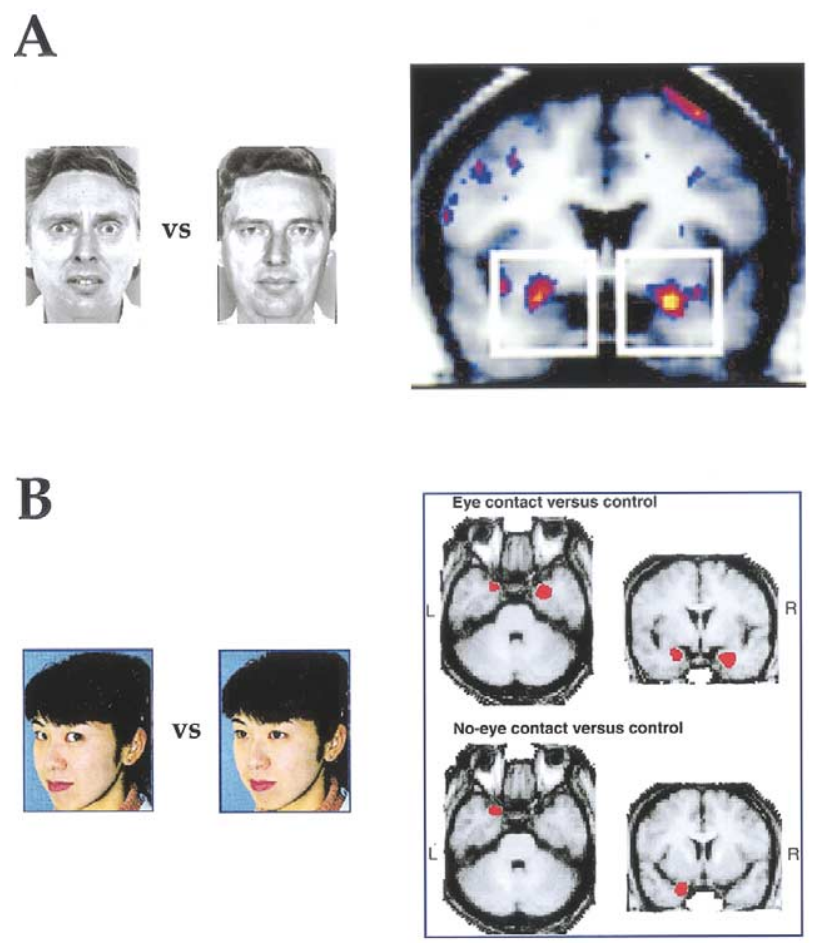

Figure 3. The amygdala shows higher rates of activity when viewing fearful facial expressions (A, adapted from Breiter et al 1996) and when viewing faces with direct gaze (B, right amygdala only, adapted from Kawashima et al 1999).

emotion in oneself. The perception of emotional expressions evokes activity in brain regions that are associated with emotion. In a magnetoencephalography (MEG) study (Streit et al 1999), judgment of emotion from expression first elicited a stronger response, as compared to simple face detection, in posterior superior temporal cortex 140 $170 \mathrm{msec}$ after stimulus onset and later elicited a response in the right amygdala with a latency of about $220 \mathrm{msec}$, providing a direct demonstration of interaction between these regions in the perception of emotion in faces.

Perception of fear in the face of another has been found consistently to evoke a response in the amygdala (Breiter et al 1996; Morris et al 1996; Phillips et al 1997, 1998) (Figure 3). The perception of disgust in the face of another has been found to evoke a response in the anterior insula in a region that presumably is also associated with processing smells and visceral sensations (Phillips et al 1997, 1998). This response may reflect the role played by disgust in rejecting foods that smell bad and are likely unsafe to eat.

The role played by the amygdala in processing facial emotion appears to be greatest for the processing fear or potential threat but also may involve aspects of social cognition that are not clearly related to fear. Studies of fear 
conditioning in rats, nonhuman primates, and humans have demonstrated that the amygdala plays a central role in processing fear (LaBar et al 1998; LeDoux 1992). Studies of patients with bilateral lesions of the amygdala have demonstrated an impairment of the ability to recognize emotions that is specific to negative emotions, such as fear and anger, suggesting a greater role for this structure in the processing of fear than in the processing of other emotions (Adolphs et al 1994; Calder et al 1996). The amygdala, however, may also play a more general role in processing information that is critical for social cognition (Adolphs 1999; Brothers 1990), such as judging the state of mind based on perception of the eye region (BaronCohen et al 1999).

Amygdala activity during face perception may also reflect emotional responses that are unrelated to the emotional expression on the face being viewed. These emotional responses may reflect the extent to which a social encounter makes one feel guarded or safe and at ease. Perception of direct gaze, for example, elicits a response in the amygdala (Kawashima et al 1999) (Figure 3 ). This response may reflect the ambiguous meaning of direct gaze in human social interactions. On the one hand, a direct gaze may indicate interest or attraction. On the other hand, direct gaze can indicate potential threat. Perception of the faces of familiar and unfamiliar individuals can also modulate activity in the amygdala. The perception of familiar faces elicits less activity in the amygdala than does perception of unfamiliar faces, and this diminution of activity is greater when viewing personally familiar faces, such as family and friends, than when viewing famous familiar faces (Gobbini et al 2000). This reduction of activity may be associated with feeling more at ease and less guarded when one is with close acquaintances as compared to when one is with strangers.

Another neural system that participates in face perception involves the orbitofrontal cortex and its role in evaluating associations with potential reward. Face-responsive neurons have been identified in the orbitofrontal cortex in the macaque (Thorpe et al 1983), and it has been suggested that the orbitofrontal cortex plays a role in evaluating the information in faces that is important for social reinforcement, including both expression and identity (Rolls 1996). Human patients with ventral frontal lesions have been found to have impaired ability to identify facial emotion expression (Hornak et al 1996).

Accurate recognition of complex emotions in facial expressions may also involve the participation of somatosensory cortex, particularly right somatosensory cortex. Adolphs (1999) has suggested that complex expressions that contain blends of emotions may be interpreted by simulating the perceived expression using somatosensory

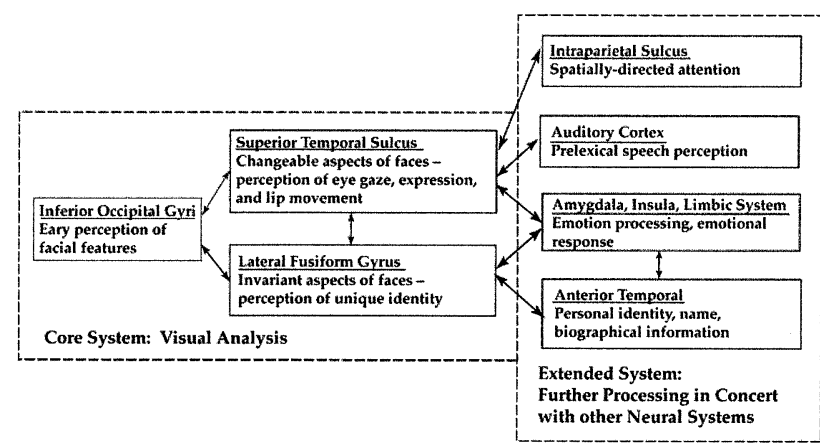

Figure 4. A model of the distributed human neural system for face perception (Haxby et al 2000). The model is divided into a core system for the visual analysis of faces, which consists of three regions of occipitotemporal visual extrastriate cortex, and an extended system for further processing of the meaning of information gleaned from faces, which consists of regions that are also parts of neural systems for other cognitive functions. Changeable and invariant aspects of the visual facial configuration have distinct representations in the core system. Interactions between these representations in the core system and regions in the extended system mediate processing of the spatial focus of another's attention, speech-related mouth movements, facial expression, and identity. Processing the emotional content of a face and the evocation of an emotional response to a face can be based on changeable aspects of the face, such as expression and eye gaze, or on identity and knowledge of the person being viewed.

cortex, either overtly or covertly, and sensing the emotion produced by that simulation.

\section{Model of a Distributed Neural System for Face Perception}

We have proposed a model of the human neural system that mediates face perception (Figure 4) (Haxby et al 2000). The model has a branching structure that emphasizes a distinction between the representation of invariant aspects of faces, which underlie recognition of unique identity, and the representation of changeable aspects of faces, which underlie perception of information that facilitates social communication. The model has a hierarchical structure that distinguishes a core system for the visual analysis of faces and an extended system that processes the meaning of information obtained from faces. The core system consists of three bilateral regions with an anatomical configuration that suggests a hierarchical organization in which the inferior occipital region may provide input to the lateral fusiform and superior temporal sulcal regions. Additional neural systems are extensions of the face perception system. The neural systems for spatial attention and perception, with brain regions in the intraparietal sulcus and, most likely, the frontal eye fields, processes 
information from faces, such as gaze direction and head position, to direct attention. The neural system for auditory verbal comprehension in the superior temporal gyrus participates in processing speech-related lip movements, presumably to extract phonemic information. Neural systems for representing biographical semantic knowledge in the anterior temporal lobe participate in retrieving the name and other information associated with a face. Systems for processing emotion, with regions identified thus far in the amygdala and insula, process the emotional content of expression.

Our model proposes that many face perception functions are accomplished by the coordinated participation of multiple regions. Processing the spatial information conveyed by gaze and head position involves the coordinated participation of the face-responsive region in the superior temporal sulcus and the spatial attention system in the intraparietal sulcus. Lip reading involves the coordinated participation of regions for the visual analysis of lip movements and for phonemic analysis. Perception of emotional expression involves the coordinated participation of regions for the visual analysis of expression and regions for the representing and producing emotions. Thus, a cognitively defined function, such as lip reading, does not involve a brain region specialized for that function but, rather, the concerted activity of regions that perform components of that function. The same regions can also participate in other functions by interacting with other systems. For example, intraparietal regions that act in concert with the superior temporal sulcus to mediate shifts of spatial attention in response to perceived gaze are also involved in directing spatial attention in response to other visual cues and, perhaps, to auditory, somatosensory, and endogenous cues as well. The investigation and modeling of interactions among the regions that comprise the distributed human neural system for face perception, therefore, are essential for developing an understanding of human face perception.

This model provides a description of functional subsystems that underlie many aspects of social cognition. Awareness of the attentional focus of another person is associated with interactions between the superior temporal sulcus and the intraparietal sulcus. Processing and reacting to the emotional state of another person is associated with interactions among the superior temporal sulcus, the amygdala, and other structures associated with emotion. In particular, the participation of the amygdala plays a role in processing facial information that may be relevant to feeling guarded or at ease in social situations. One's emotional response to direct eye gaze, a social signal that can be both attractive and challenging, is associated in part with interactions between the superior temporal sulcus and the amygdala. One's feeling of being guarded with strang- ers or at ease with friends may be associated with interactions among the lateral fusiform gyrus, anterior temporal regions, and the amygdala. Thus, the study of face perception and its underlying neural mechanisms may provide a framework and a set of methods for probing normal and disordered social cognition.

Aspects of this work were presented at the conference, "Social Anxiety: From Laboratory Studies to Clinical Practice," held March 22, 2001 in Atlanta, Georgia. The conference was supported by an unrestricted educational grant to the Anxiety Disorders Association of America (ADAA) from Wyeth-Ayerst Pharmaceuticals, and jointly sponsored by the ADAA, the ADAA Scientific Advisory Board, and the National Institute of Mental Health.

\section{References}

Adolphs R (1999): Social cognition and the human brain. Trends Cogn Sci 3:469-479.

Adolphs R, Tranel D, Damasio H, Damasio A (1994): Impaired recognition of emotion in facial expression following bilateral damage to the human amygdala. Nature 372:669-672.

Allison T, Puce A, Spencer DD, McCarthy G (1999): Electrophysiological studies of human face perception I: Potentials generated in occipitotemporal cortex by face and non-face stimuli. Cereb Cortex 9:415-430.

Baron-Cohen S (1995): The eye direction detector (EDD) and the shared attention mechanism (SAM): Two cases for evolutionary psychology. In: Moore C, Dunham PJ, editors. Joint Attention: Its Origins and Role in Development. New York: Lawrence Erlbaum, 41-59.

Baron-Cohen S, Ring HA, Wheelwright S, Bullmore ET, Brammer MJ, Simmons A, et al (1999): Social intelligence in the normal and autistic brain: An fMRI study. Eur J Neurosci 11:1891-1898.

Benton A (1980): The neuropsychology of facial recognition. Am Psychol 35:176-186.

Bonda E, Petrides M, Ostry D, Evans A (1996): Specific involvement of human parietal systems and the amygdala in the perception of biological motion. J Neurosci 16:37373744.

Breiter H, Etcoff NL, Whalen PJ, Kennedy WA, Rauch SL, Buckner RL (1996): Response and habituation of the human amygdala during visual processing of facial expression. Neuron 17:875-887.

Brothers L (1990): The social brain: A project for integrating primate behavior and neurophysiology in a new domain. Concepts Neurosci 1:27-51.

Bruce V, Young A (1986): Understanding face recognition. Br J Psychol 77:305-327.

Calder AJ, Young AW, Rowland D, Perrett DI, Hodges JR, Etcoff NL (1996): Facial emotion recognition after bilateral amygdala damage: Differentially severe impairment of fear. Cogn Neuropsychol 13:699-745.

Calvert G, Bullmore ET, Brammer MJ, Campbell R, Williams SCR, McGuire PK, et al (1997): Activation of auditory cortex during silent lipreading. Science 276:593-596. 
Chao LL, Haxby JV, Martin, A (1999a): Attribute-based neural substrates in temporal cortex for perceiving and knowing objects. Nat Neurosci 2:913-919.

Chao LL, Martin, A, Haxby, JV (1999b): Are face-responsive regions selective only for faces? Neuroreport 10:2945-2950.

Clark VP, Keil K, Maisog JM, Courtney SM, Ungerleider LG, Haxby JV (1996): Functional magnetic resonance imaging of human visual cortex during face matching: a comparison with positron emission tomography. Neuroimage 4:1-15.

Colby C, Goldberg M (1999): Space and attention in parietal cortex. Annu Rev Neurosci 22:319-349.

Corbetta M, Miezin Fm, Shulman GI, Petersen SE (1993): A PET study of visuospatial attention. J Neurosci 13:12021226.

Corbetta M (1998): Frontoparietal cortical networks for directing attention and the eye to visual locations: Identical, independent, or overlapping neural systems? Proc Natl Acad Sci USA 95:831-838.

Damasio A, Damasio H, Van Hoesen G (1982): Prosopagnosia: Anatomic basis and behavioral mechanisms. Neurology 32 331-341.

Decety J, Grezes J (1999): Neural mechanisms subserving the perception of human actions. Trends Cogn Sci 3:172-178.

De Renzi E (1986): Prosopagnosia in two patients with CT scan evidence of damage confined to the right hemisphere. $\mathrm{Neu}$ ropsychologia 24:385-389.

Desimone R (1991): Face-selective cells in the temporal cortex of monkeys. J Cogn Neurosci 3:1-8.

Driver J, Davis G, Ricciardelli P, Kidd P, Maxwell E, BaronCohen $S$ (1999): Gaze perception triggers reflexive visuospatial orienting. Vis Cogn 6:509-540.

Ellis AW (1992): Cognitive mechanisms of face processing. Phil Trans $R$ Soc Lond B 335:113-119.

Friesen CK, Kingstone, A (1998): The eyes have it! Reflexive orienting is triggered by nonpredictive gaze. Psychon Bull Rev 5:490-495.

Gauthier I, Skudlarski P, Gore JC, Anderson AW (2000): Expertise for cars and birds recruits brain areas involved in face recognition. Nat Neurosci 3:191-197.

Gauthier I, Tarr MJ, Anderson AW, Skudlarski P, Gore JC (1999): Activation of the middle fusiform "face area" increases with expertise in recognizing novel objects. Nat Neurosci 2:568-573.

George N, Dolan RJ, Fink GR, Baylis GC, Russell C, Driver J (1999): Contrast polarity and face recognition in the human fusiform gyrus. Nat Neurosci 2:574-580.

Gobbini MI, Leibenluft E, Santiago NJ, Haxby JV (2000): The effect of personal familiarity on the neural response to faces. Soc Neurosci Abstr 26:974.

Gorno Tempini M, Price CJ, Josephs O, Vandenberghe R, Cappa SF, Kapur N, et al (1998): The neural systems sustaining face and proper name processing. Brain 121:2103-2118.

Halgren E, Dale AM, Sereno MI, Tootell RBH, Marinkovic K, Rosen BR (1999): Location of human face-selective cortex with respect to retinotopic areas. Hum Brain Mapp 7:29-37.

Harries M, Perrett D (1991): Visual processing of faces in temporal cortex: Physiological evidence for a modular organization and possible anatomical correlates. J Cogn Neurosci $3: 9-24$.
Hasselmo M, Rolls E, Baylis G (1989): The role of expression and identity in the face-selective responses of neurons in the temporal visual cortex of the monkey. Behav Brain Res 32:203-218.

Haxby JV, Gobbini MI, Furey ML, Ishai A, Schouten JL, Pietrini P (2001): Distributed and overlapping representations of faces and objects in ventral temporal cortex. Science 293: $2425-2430$.

Haxby JV, Hoffman EA, Gobbini MI (2000): The distributed human neural system for face perception. Trends Cogn Sci 4:223-233.

Haxby JV, Horwitz B, Ungerleider LG, Maisog JM, Pietrini P, Grady CL (1994): The functional organization of human extrastriate cortex: A PET-rCBF study of selective attention to faces and locations. J Neurosci 14:6336-6353.

Haxby JV, Ungerleider LG, Clark VP, Schouten JL, Hoffman EA, Martin A (1999): The effect of face inversion on activity in human neural systems for face and object perception. Neuron 22:189-199.

Hecaen H, Angelergues R (1962): Agnosia for faces (Prosopagnosia). Arch Neurol 7:24-32.

Hietanen J (1999): Does your gaze direction and head orientation shift my visual attention? Neuroreport 10:3443-3447.

Hilgetag CC, Theoret H, Pascual-Leone A (2001) Enhanced visual spatial attention ipsilateral to rTMS-induced "virtual lesions" of human parietal cortex. Nat Neurosci 4:953-957.

Hoffman E, Haxby J (2000): Distinct representations of eye gaze and identity in the distributed human neural system for face perception. Nat Neurosci 3:80-84.

Hood B, Willen J, Driver J (1998): Adult's eyes trigger shifts of visual attention in human infants. Psychol Sci 9:131-134.

Hornak J, Rolls ET, Wade D (1996): Face and voice expression identification in patients with emotional and behavioural changes following ventral frontal lobe damage. Neuropsychologia 34:247-261.

Ishai A, Ungerleider LG, Martin A, Schouten JL, Haxby JV (1999): Distributed representation of objects in the human ventral visual pathway. Proc Natl Acad Sci USA 96:93799384.

Kanwisher N, McDermott J, Chun MM (1997): The Fusiform Face Area: A module in human extrastriate cortex specialized for face perception. $J$ Neurosci 17:4302-4311.

Kawashima R, Sugiura M, Kato T, Nakamura A, Hatano K, Ito $\mathrm{K}$, et al (1999): The human amygdala plays an important role in gaze monitoring: A PET study. Brain 122:779-783.

LaBar KS, Gatenby JC, Gore JC, LeDoux JE, Phelps EA (1998): Human amygdala activation during conditioned fear acquisition and extinction: a mixed-trial fMRI study. Neuron 20: 937-945.

Landis T, Cummings JL, Christen L, Bogen JE, Imhof HG (1986): Are unilateral right posterior cerebral lesions sufficient to cause prosopagnosia? Clinical and radiological findings in six additional cases. Cortex 22:243-252.

Langton SRH, Bruce V (1999): Reflexive visual orienting in response to the social attention of others. Vis Cogn 6:541568.

Langton SRH, Watt RJ, Bruce V (2000): Do the eyes have it? Cues to the direction of social attention. Trends Cogn Sci $4: 50-59$. 
LeDoux J (1992): Emotion and the amygdala. In: Aggleton J, editor. The Amygdala: Neurobiological Aspects of Emotion, Memory, and Mental Dysfunction. New York: John Wiley \& Sons, 339-351.

Leveroni CL, Seidenberg M, Mayer AR, Mead LA, Binder JR, Rao SM (2000): Neural systems underlying the recognition of familiar and newly learned faces. J Neurosci 20:878-886.

McCarthy G, Puce A, Belger A, Allison T (1999): Electrophysiological studies of human face perception II: Response properties of face-specific potentials generated in occipitotemporal cortex. Cereb Cortex 9:431-444.

McCarthy G, Puce A, Gore JC, Allison T (1997): Face-specific processing in the human fusiform gyrus $J$ Cogn Neurosci 9:605-610

McGurk H, MacDonald J (1976): Hearing lips and seeing voices. Nature 264:746-748.

McNeil J, Warrington, E (1993): Prosopagnosia: A face-specific disorder. $Q J$ Exp Psychol 46A:1-10.

Morris JS, Frith CD, Perrett DI, Rowland D, Young AW, Calder AJ, et al (1996): A differential neural response in the human amygdala to fearful and happy facial expressions. Nature 383:812-815.

Morton J, Johnson M (1991): CONSPEC and CONLEARN: A two-process theory of infant face recognition. Psychol Rev 98:164-181.

Nakamura K, Kawashima R, Sato N, Nakamura A, Sugiura M, Kato T, et al (2000): Functional delineation of the human occipito-temporal areas related to face and scene processing: A PET study. Brain 123:1903-1912.

Nobre AC, Sebestyen GN, Gitelman DR, Mesulam MM, Frackowiak RSJ, Frith CD (1997): Functional localization of the system for visuospatial attention using positron emission tomography. Brain 120:515-533.

Perrett D, Harries MF, Mistlin AJ, Hietanen JK, Benson PJ, Bevan R, et al (1990): Social signals analyzed at the single cell level: Someone is looking at me, something touched me, something moved! Int J Comp Psychol 4:25-55.

Perrett D, Mistlin A (1990): Perception of facial characteristics by monkeys. In: Stebbins W, Berkley M, editors. Comparative Perception, Vol 2. New York: John Wiley \& Sons, 187-215.

Perrett D, Rolls E, Caan W (1982): Visual neurones responsive to faces in the monkey temporal cortex. Exp Brain Res 47:329-342.

Perrett DI, Hietanen JK, Oram MW, Benson PJ (1992): Organi- zation and functions of cells responsive to faces in the temporal cortex. Phil Trans R Soc Lond 335:25-30.

Perrett DI, Smith PAJ, Potter DD, Mistlin AJ, Head AS, Milner AD, et al (1984): Neurones responsive to faces in the temporal cortex: studies of functional organization, sensitivity to identity and relation to perception. Hum Neurobiol 3:197-208.

Perrett DI, Smith PAJ, Potter DD, Mistlin AJ, Head AS, Milner AD, et al (1985): Visual cells in the temporal cortex sensitive to face view and gaze direction. Proc $R$ Soc Lond $B$ 223:293-317.

Phillips ML, Young AW, Scott SK, Calder AJ, Andrew C, Giampietro V, et al (1998): Neural responses to facial and vocal expressions of fear and disgust. Proc $R$ Soc Lond $B$ 265:1809-1817.

Phillips ML, Young AW, Senior C, Brammer M, Andrew C, Calder AJ, et al (1997): A specific neural substrate for perceiving facial expressions of disgust. Nature 389:495498.

Puce A, Allison T, Bentin S, Gore JC, McCarthy G, et al (1998): Temporal cortex activation of humans viewing eye and mouth movements. J Neurosci 18:2188-2199.

Puce A, Allison T, McCarthy G (1999): Electrophysiological studies of human face perception III: Effects of top-down processing on face-specific potentials. Cereb Cortex 9:445458.

Rolls E (1996): The orbitofrontal cortex. Phil Trans $R$ Soc Lond B 351:1433-1444.

Sergent J, Ohta S, MacDonald B (1992): Functional neuroanatomy of face and object processing. Brain 115:15-36.

Sergent J, Signoret J (1992): Varieties of functional deficits in prosopagnosia. Cereb Cortex 2:375-388.

Streit M, Ioannides AA, Liu L, Wolwer W, Dammers J, Gross J et al (1999): Neurophysiological correlates of the recognition of facial expressions of emotion as revealed by magnetoencephalography. Cogn Brain Res 7:481-491.

Thorpe SJ, Rolls ET, Maddison S (1983): Neuronal activity in the orbitofrontal cortex of the behaving monkey. Exp Brain Res 49:93-115.

Ungerleider L, Mishkin M (1982): Two cortical visual systems. In: Ingle D, Goodale M, Mansfield R, editors. Analysis of Visual Behavior. Cambridge, MA: MIT Press, 549-586.

Vecera S, Johnson M (1995): Gaze detection and the cortical processing of faces: Evidence from infants and adults. Vis Cogn 2:59-87. 